\title{
OBTENÇÃO E CARACTERIZAÇÃO DE CARVÃO ATIVADO SINTETIZADO A PARTIR DA CASCA DO MARACUJÁ AMARELO (Passiflora edulis) VISANDO À REMOÇÃO DE FENOL
}

\author{
T. F. SOUZA ${ }^{1}$, E. de JESUS ${ }^{1}$ \\ ${ }^{1}$ Universidade Federal de Sergipe, Departamento de Engenharia Química \\ E-mail para contato: tiagofs799@gmail.com
}

\begin{abstract}
RESUMO - Neste estudo, carvão ativado sintetizado a partir da casca do maracujá amarelo foi caracterizado e utilizado em testes preliminares de remoção de fenol de soluções aquosas. Logo, análises de área superficial e volume dos poros, MEV, FRX, determinação do $\mathrm{pH}$ ponto de carga zero foram realizadas, bem como testes em banho finito de remoção de fenol. O carvão ativado apresentou área superficial de $464,4830 \mathrm{~m}^{2} \mathrm{~g}^{-1}$, volume dos poros de $0,2880 \mathrm{~cm}^{3} \mathrm{~g}^{-1}$ e diâmetro médio dos poros de $3,173 \mathrm{~nm}$. A maior remoção de fenol de soluções aquosas em carvão ativado sintetizado a partir da casca do maracujá amarelo (Passiflora edulis) foi 81,6\%, em $\mathrm{pH} 2$ que coincidentemente foi determinado como o $\mathrm{pH}$ ponto de carga zero do carvão.
\end{abstract}

\section{INTRODUÇÃO}

O carvão ativado tem sido amplamente utilizado no processo de adsorção de compostos orgânicos (Dabrowski et al., 2005; Beker et al., 2010; Lorenc-Grabowska et al., 2013; Giraldo e Moreno-Piraján, 2014). Esse material possui, geralmente, elevada área superficial, alta porosidade e uma variedade de grupos funcionais em sua estrutura o que lhe confere uma capacidade de adsorção elevada se comparada com a de outros materiais (Guilarduce et al., 2006; Dabrowski et al., 2005).

A matéria-prima utilizada na produção de carvão ativado deve possuir alto teor de carbono, baixo custo, ter disponibilidade, ser de fácil ativação e ter baixa degradabilidade durante o armazenamento (Inglezakis e Poulopoulos, 2006; Dabrowski et al., 2005). Os resíduos agroindustriais estão sendo amplamente utilizados em estudos como material precursor para produção de carvão ativado (Jaguaribe et al., 2005; Adinaveen et al., 2013; Fernandez et al., 2014; Köseglu e Basa, 2015). A casca do maracujá amarelo (Passiflora edulis) é um material carbonáceo, altamente disponível no Brasil, em especial na região nordeste nos estados da Bahia, Sergipe e Ceará. Portanto, esse resíduo agroindustrial apresenta potencial para ser utilizado como matéria-prima na obtenção do carvão ativado.

A obtenção do carvão ativado é realizada a partir de duas etapas básicas, a carbonização da matéria precursora através da pirólise e a ativação propriamente dita (Schneider, 2008). A ativação pode ser realizada através de uma rota química ou física (Jaguaribe et al., 2005). No processo de ativação física, o material carbonizado é gaseificado, geralmente, com vapor 
d'água, ou dióxido de carbono. Na ativação química, o material precursor é impregnado com um agente químico capaz de oxidá-lo e desidratá-lo durante o processo de pirólise, sendo o $\mathrm{H}_{3} \mathrm{PO}_{4}, \mathrm{ZnCl}_{2}$ e $\mathrm{KOH}$ os agentes químicos mais comumente utilizados.

Nesse contexto, este trabalho teve como âmago a sintetização e caracterização de carvão ativado produzido a partir da casca de maracujá amarelo, bem como o desenvolvimento de estudos preliminares de remoção de fenol de soluções aquosas.

\section{METODOLOGIA}

A metodologia utilizada para produzir o carvão ativado a partir da casca do maracujá amarelo, para caracterização do adsorvente e para os testes preliminares de remoção de fenol de soluções aquosas estão descritas nas seções que seguem.

\subsection{Obtenção do carvão ativado}

A casca do maracujá amarelo (Passiflora edulis) após a lavagem com água destilada, trituramento e secagem passou por um pré-tratamento antes da carbonização com uma solução do agente ativante $\mathrm{H}_{3} \mathrm{PO}_{4}$ P.A. $85 \%$ (NEON). A ação desse reagente se deu a uma temperatura de $85{ }^{\circ} \mathrm{C}$, durante uma hora, em um becker. Foi utilizado $150 \mathrm{~mL}$ de $\mathrm{H}_{3} \mathrm{PO}_{4} 85 \%$ para cada 15 $\mathrm{g}$ do material precursor. Nesta etapa o material permaneceu sob agitação constante para garantir uniformidade na mistura e a plena ação do agente químico sobre a matéria-prima. Após isto, o resíduo sólido impregnado com o agente ativante, material úmido de cor preta, foi colocado em cadinhos e seco em estufa por um período de 24 hora a $85^{\circ} \mathrm{C}$. Após a secagem o material foi carbonizado em um reator tubular, acoplado a um forno elétrico EDGCON 10P, de acordo com ilustração esquemática da Figura 1, a temperatura máxima de $700{ }^{\circ} \mathrm{C}$, empregando-se uma razão de aquecimento de $15^{\circ} \mathrm{C} \mathrm{min}{ }^{-1}$ por duas horas sob taxa de nitrogênio de $1 \mathrm{~L} \mathrm{~min}^{-1}$ para tornar o ambiente inerte. Após a carbonização e ativação, o carvão ativado obtido foi lavado a quente com água destilada até o $\mathrm{pH}$ da água de lavagem não apresentar variação significativa. A finalidade da lavagem foi a retirada do excesso do reagente utilizado no pré-tratamento, bem como a remoção das impurezas provenientes do processo carbonização e ativação.

Figura 1 - Esquematização do processo de produção do carvão ativado: controlador do forno do elétrico (1); saída dos gases (2); forno elétrico (3); entrada de $\mathrm{N}_{2(\mathrm{~g})}$ (4); controlador da vazão de $\mathrm{N}_{2(\mathrm{~g})}$ (5); cilindro de $\mathrm{N}_{2(\mathrm{~g})}(6)$.

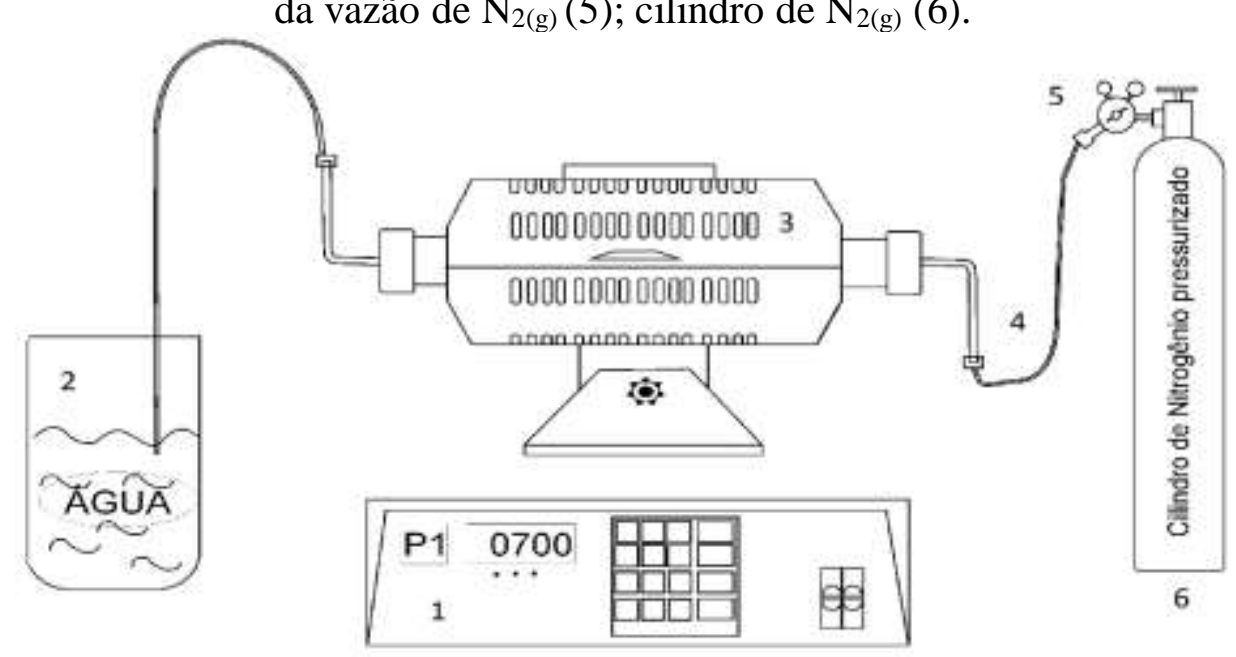




\subsection{Caracterização do carvão ativado}

A caracterização do carvão ativado foi realizada a partir das análises de determinação da área superficial específica e volume de poros, MEV e a análise química FRX.

Determinação da área superficial e volume dos poros: A determinação da área superficial e volume dos poros do carvão ativado foi realizada em um analisador de área superficial, volume e distribuição de poros Micromeritics, modelo ASAP 2020. Foi utilizado o princípio de Brunauer-Emmett-Teller (BET), segundo Jaguaribe et al. (2005), na determinação das características texturais do adsorvente.

Microscopia eletrônica de varredura (MEV): Foram obtidas as micrografias de varredura eletrônica do carvão ativado antes do processo de adsorção. As análises foram feitas em microscópio eletrônico de varredura da marca LEO, modelo $1430 \mathrm{VP}$, sob vácuo, com aceleração de feixe de $5 \mathrm{kV}$. Todas as amostras foram previamente metalizadas com ouro (espessura média de $11 \mathrm{~nm}$ ). Está análise se justifica para verificar visualmente a forma e estrutura do adsorvente.

Fluorescência de Raios X (FRX): A composição química do adsorvente antes da adsorção foi determinada através da análise química de Fluorescência de Raios X. A amostra de adsorvente foi previamente misturada com ácido bórico e em seguida prensada, obtendo-se uma pastilha consistente. Em seguida a amostra foi colocada em uma cubeta e inserida no espectrofotômetro FRX Bruker S8 Tiger para que a análise química fosse realizada.

\subsection{Determinação da concentração de fenol de soluções aquosas}

A concentração de fenol em soluções aquosas foi determinada por espectrofotometria de absorção atômica. As absorbâncias das amostras contendo fenol foram medidas em espectrofotômetro UV-Visível da Biospectro, modelo SP-220. O comprimento de onda utilizado foi $270 \mathrm{~nm}$. A curva de calibração foi obtida utilizando soluções padrão de fenol na faixa de 5 a $150 \mathrm{mg} \mathrm{L}^{-1}$. Os valores de concentração das amostras contendo fenol foram estimados através da curva de calibração.

\subsection{Determinação do $\mathrm{pH}$ ponto de carga zero $\left(\mathrm{pH}_{\mathrm{pcz}}\right)$}

$\mathrm{O} \mathrm{pH}$ do ponto de carga zero $\left(\mathrm{pH}_{\mathrm{pcz}}\right)$ do carvão ativado foi determinado através de medidas do $\mathrm{pH}$ da água destilada antes e após o contato com o adsorvente. Foram adicionados $0,05 \mathrm{~g}$ do adsorvente em $50 \mathrm{~mL}$ de água com pH inicial da água destilada variando de 2 a 10 . $\mathrm{O}$ pH inicial da água destilada foi ajustado com soluções de ácido clorídrico $\left(0,1 \mathrm{~mol} \mathrm{~L}^{-1}\right)$ e hidróxido de sódio $\left(0,1 \mathrm{~mol} \mathrm{~L}^{-1}\right)$. Estas soluções ficaram sob agitação de $150 \mathrm{rpm}$ em agitador Nova Ética, Modelo 109, por 12 horas. $\mathrm{O} \mathrm{pH}_{\mathrm{pcz}}$ foi obtido pelo gráfico $\left(\mathrm{pH}_{\text {final }}-\mathrm{pH}_{\text {inicial }}\right)$ em função do $\mathrm{pH}_{\text {inicial}}$, na interseção da curva com o eixo $\mathrm{pH}_{\text {inicial }}$.

\subsection{Efeito do pH na remoção de fenol de soluções aquosas}

Foram realizados testes em triplicata variando o $\mathrm{pH}$ inicial da solução aquosa contendo fenol a fim de analisar a influência desse parâmetro no processo de adsorção. Os valores de $\mathrm{pH}$ utilizados foram 2, 4, 6, 8 e 10. A massa de adsorvente utilizada foi $0,05 \mathrm{~g}$ e o volume de solução 
aquosa contendo fenol foi $50 \mathrm{~mL}$. A concentração inicial de fenol utilizada foi de $20 \mathrm{ppm}$. As soluções ficaram sob agitação constante de $150 \mathrm{rpm}$ por um período de 3 horas, sendo a temperatura de processo de $25^{\circ} \mathrm{C}$. A porcentagem de remoção de fenol de soluções aquosas foi determinada pela Equação 1, em que $C_{i}\left(\mathrm{mg} \mathrm{L}^{-1}\right)$ é a concentração inicial da amostra contendo fenol e $C_{f}\left(\mathrm{mg} \mathrm{L}^{-1}\right)$ a concentração da amostra após o processo de adsorção.

$$
\% \text { Remoção de fenol }=\frac{\left(C_{i}-C_{f}\right)}{C_{i}} 100
$$

\section{RESULTADOS E DISCUSSÃO}

Os resultados e as discussões referentes a caracterização do carvão ativado produzido a partir da casca do maracujá amarelo (Passiflora edulis) e dos testes preliminares de remoção de fenol estão dispostos nas seções subsequentes.

\subsection{Determinação da área superficial e volume dos poros}

A Tabela 1 ilustra as propriedades físicas do carvão ativado a partir da casca de maracujá amarelo. Tais propriedades foram medidas usando a adsorção $\mathrm{N}_{2(\mathrm{~g})}$ a $77 \mathrm{~K}$, de acordo com Jaguaribe et al. (2005).

Tabela 1 - Propriedades físicas do carvão ativado produzido a partir da casca do maracujá amarelo (Passiflora edulis)

\begin{tabular}{cc}
\hline Propriedades & Valores \\
\hline Área superficial específica $\left(\mathrm{S}_{\mathrm{BET}}\right)\left(\mathrm{m}^{2} \mathrm{~g}^{-1}\right)$ & 464,4830 \\
Volume total de poros $\left(\mathrm{cm}^{3} \mathrm{~g}^{-1}\right)$ & 0,2880 \\
Tamanho médio das partículas $(\mathrm{nm})$ & 12,918 \\
Diâmetro médio dos poros $(\mathrm{nm})$ & 3,173 \\
\hline
\end{tabular}

Fonte: Elaborada pelo autor

O carvão ativado apresenta uma área superficial específica ( $\mathrm{S}_{\mathrm{BET}}$ ) de 464,4830 $\mathrm{m}^{2} \mathrm{~g}^{-1}$, vide Tabela 1. Segundo Inglezakis e Poulopoulos (2006), os carvões ativados comerciais apresentam, geralmente, área superficial entre 300 e $1500 \mathrm{~m}^{2} \mathrm{~g}^{-1}$, logo o carvão ativado produzido a partir da casca do maracujá amarelo apresenta área superficial especifica dentro dessa faixa, indicando que a obtenção do carvão se enquadrou nos processos convencionais de produção. $\mathrm{O}$ material apresentou volume total de poros igual a $0,2880 \mathrm{~cm}^{3} \mathrm{~g}^{-1}$.

O tamanho médio das partículas e o diâmetro médio dos poros para o carvão foram, respectivamente, $12,918 \mathrm{~nm}$ e $3,173 \mathrm{~nm}$. De acordo com Inglezakis e Poulopoulos (2006), o material poroso pode ser dividido em três classes de acordo com o diâmetro (d) dos poros: macroporoso $(\mathrm{d}>50 \mathrm{~nm})$, mesoporoso $(2<\mathrm{d}<50 \mathrm{~nm})$ e microsporoso $(\mathrm{d}<2 \mathrm{~nm})$. De acordo com essa classificação, o carvão ativado produzido a partir da casca do maracujá amarelo é predominantemente mesoporoso. 


\subsection{Microscopia Eletrônica de Varredura (MEV)}

As características morfológicas do carvão ativado produzido a partir da casca de maracujá amarelo antes de serem realizados quaisquer testes de remoção estão ilustradas na Figura 2, que correspondem as micrografias de varredura eletrônica do material.

Figura 2 - Micrografias de Varredura Eletrônica do carvão ativado produzido a partir da casca do maracujá amarelo antes de serem realizados testes de remoção: ampliada 1000x (a), ampliada 1000x (b).

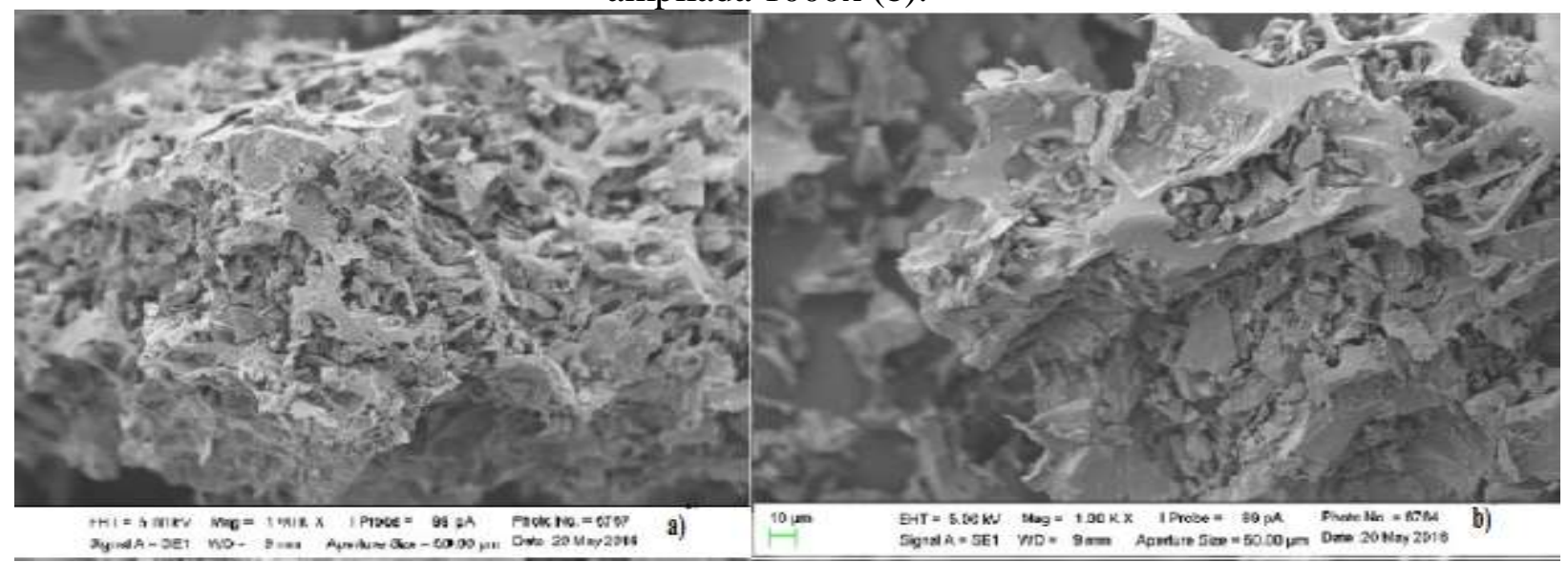

Fonte: Elaborada pelo autor

Ao analisar a Figura 2, nota-se que o material possui uma superfície extremamente irregular e porosa, indicando a presença de uma área superficial específica razoavelmente elevada e como consequência um provável potencial adsortivo elevado. Foi visto no item 3.1. que o carvão ativado apresenta uma área superficial específica ( SETT $_{\text {BE }}$ de $464,4830 \mathrm{~m}^{2} \mathrm{~g}^{-1}$, o que corrobora com a análise discutida acima sobre as características morfológicas deste material.

\subsection{Fluorescência de Raios X (FRX)}

O ensaio utilizando a técnica de FRX permitiu determinar os constituintes inorgânicos do carvão ativado produzido a partir da casca do maracujá amarelo antes do processo de adsorção a partir da análise dos principais óxidos que constituem esse material. A Tabela 2 ilustra as porcentagens em massa dos principais óxidos constituintes da amostra de carvão.

Tabela 2 - Composição química do carvão ativado produzido a partir da casca do maracujá amarelo obtida através da técnica de Fluorescência de Raio X (FRX)

Elementos Composição dos óxidos no carvão ativado

\begin{tabular}{cc} 
& $(\%)$ \\
\hline $\mathrm{P}_{2} \mathrm{O}_{5}$ & 92,58 \\
$\mathrm{CaO}$ & 3,20 \\
$\mathrm{SO}_{3}$ & 1,89 \\
$\mathrm{MgO}$ & 1,07 \\
$\mathrm{SiO}_{2}$ & 0,74 \\
$\mathrm{Al}_{2} \mathrm{O}_{3}$ & 0,38 \\
$\mathrm{Fe}_{2} \mathrm{O}_{3}$ & 0,15 \\
\hline
\end{tabular}


A análise dos resultados presentes na Tabela 2 indicam a presença do fósforo como principal constituinte inorgânico do carvão ativado produzido a partir da casca do maracujá amarelo. Tal elemento foi utilizado como agente ativante durante o processo de produção do carvão, e, segundo Gondim et al. (2005), o fósforo é o principal micronutriente presentes na casca do maracujá amarelo, logo a composição majoritária deste elemento no carvão ativado é justificável. Os elementos ferro, cálcio e magnésio são micronutrientes absorvidos pelo material precursor (maracujá amarelo) durante sua formação e se mantiveram no carvão ativado após seu processo de síntese.

\subsection{Determinação do $\mathrm{pH}$ ponto de carga zero $\left(\mathrm{pH}_{\mathrm{pcz}}\right)$}

O ponto de carga zero é definido como o $\mathrm{pH}$ em que a superfície do adsorvente possui carga neutra (Guilarduce et al., 2006). A Figura 3 ilustra o gráfico de $\left(\mathrm{pH}_{\text {final }}-\mathrm{pH}_{\text {inicial }}\right)$ em função do $\mathrm{pH}_{\text {inicial }}$ para o carvão ativado produzido a partir da casca do maracujá amarelo.

Figura 1- Ponto de carga zero $\left(\mathrm{pH}_{\mathrm{pcz}}\right)$ do carvão ativado produzido a partir da casca do maracujá amarelo.

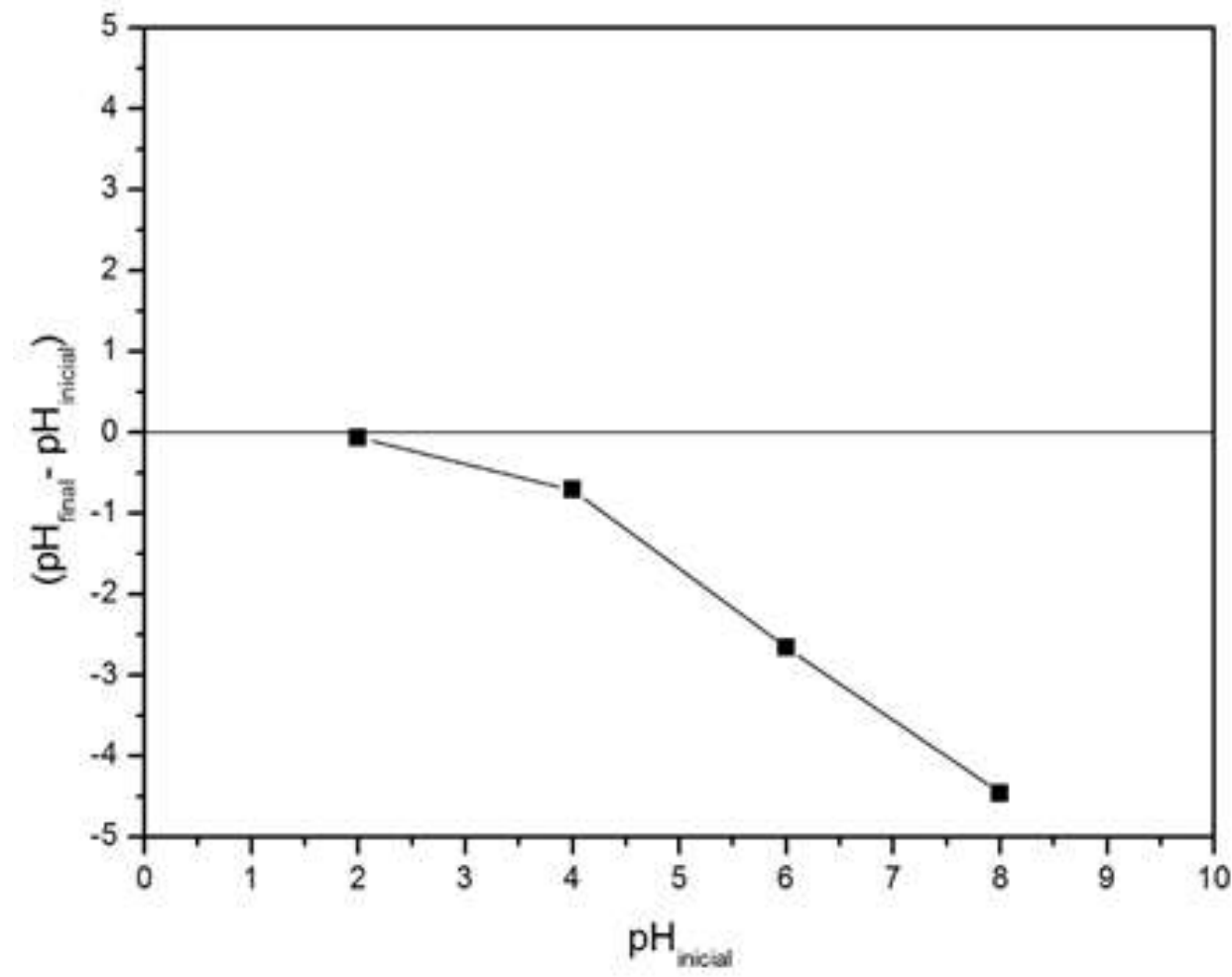

Fonte: Elaborada pelo autor

Analisando a Figura 3 pode-se afirmar que o adsorvente possui uma superfície ácida, pois o $\mathrm{pH}_{\mathrm{pcz}}$ obtido experimentalmente foi, aproximadamente, igual a 2. Este resultado sugere que a superfície do carvão ativado seja caracterizada por uma elevada quantidade de grupos funcionais ácidos em detrimento dos grupos básicos.

Em soluções com pH inferior a 2, a superfície do carvão ativado produzido a partir da casca do maracujá amarelo estará carregada positivamente, favorecendo a sorção de espécies aniônicas a fim de balancear as cargas positivas presentes em sua superfície. Por outro lado, em 
soluções cujo $\mathrm{pH}$ é superior a 2, a superfície do adsorvente estará carregada negativamente, sorvendo preferencialmente espécies catiônicas.

\subsection{Influência do pH na remoção de fenol de soluções aquosas}

No processo de adsorção, alterações no pH da solução que contém o adsorvato podem gerar modificações na carga superficial do adsorvente e na forma como o adsorvato se encontra em solução, podendo aumentar ou diminuir a atração entre a espécie a ser adsorvida e a superfície do adsorvente. Logo, é necessário determinar em qual pH da solução há uma maior interação entre adsorvato e o adsorvente que favoreça o processo e qual o comportamento adsortivo do material quando há uma variação nesse parâmetro. A Figura 4 ilustra os resultados obtidos para a remoção de fenol de soluções aquosas em função do $\mathrm{pH}$.

Figura 2 - Efeito do pH na remoção de fenol de soluções aquosas. Condições experimentais: concentração inicial de fenol de $20 \mathrm{mg} \mathrm{L}^{-1}$; quantidade de adsorvente utilizada de $0,05 \mathrm{~g}$; temperatura de $25 \pm 1^{\circ} \mathrm{C}$; velocidade de agitação de $150 \mathrm{rpm}$; tempo de contato de $180 \mathrm{~min}$.

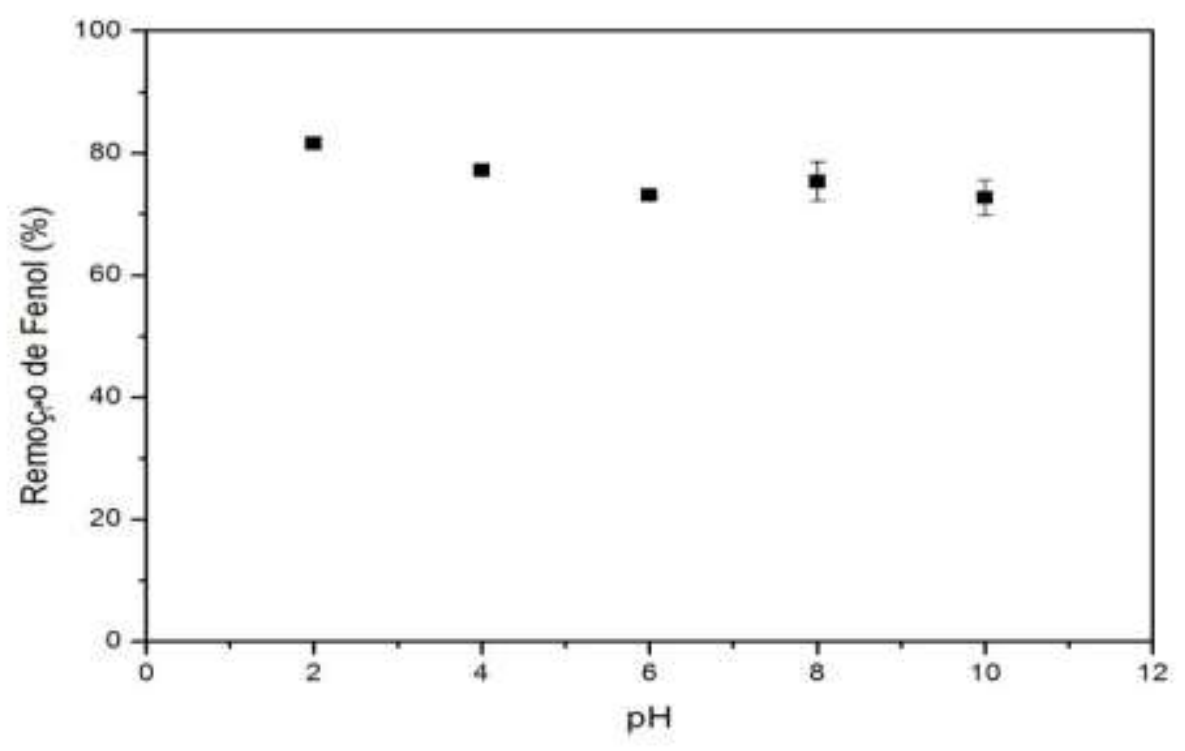

Fonte: Elaborada pelo autor

De acordo com os resultados ilustrados na Figura 4, o aumento do $\mathrm{pH}$ não levou a um aumento na remoção de fenol de soluções aquosas, sendo a máxima remoção obtida em pH igual a 2, cujo valor foi aproximadamente $81,6 \%$, indicando que o carvão ativado produzido a partir da casca de maracujá amarelo é eficiente na remoção de fenol de soluções aquosas. É válido ressaltar que a diferença entre a máxima e a mínima remoção de fenol obtida em função do $\mathrm{pH}$ foi $10,88 \%$.

O fenol estará completamente dissociado em soluções aquosas quando o pH da mesma for próximo de 10 , pois seu $\mathrm{pK}_{\mathrm{a}}$ a $25^{\circ} \mathrm{C}$ é aproximadamente $9,89, \operatorname{logo}$, à medida em que o $\mathrm{pH}$ diminui o grau de ionização do fenol também decresce (Vidic et al., 1993). O carvão ativado utilizado no teste de remoção de fenol aqui discutido apresentou $\mathrm{pH}_{\mathrm{pcz}}$ igual a 2 , neste $\mathrm{pH}$ a 
superfície do adsorvente possui carga nula. De acordo com o que foi explicitado anteriormente e sabendo que a maior remoção de fenol foi obtida em $\mathrm{pH}$ igual a 2, pode-se afirmar que a adsorção de fenol de soluções aquosas em carvão ativado produzido a partir da casca de maracujá (Passiflora edulis) não é significativamente influenciada pela carga superficial do adsorvente.

\section{CONCLUSÃO}

Pôde-se, através dos resultados expostos e discutidos neste trabalho, compreender as características morfológicas do carvão ativado sintetizado a partir da casca do maracujá amarelo, bem como assimilar de forma preliminar o comportamento adsortivo desse material na remoção de fenol de soluções aquosas.

O carvão ativado obtido a partir da casca do maracujá amarelo (Passiflora edulis) apresentou área superficial específica $\left(\mathrm{S}_{\mathrm{BET}}\right)$ de $464,4830 \mathrm{~m}^{2} \mathrm{~g}^{-1}$, tamanho médio de partículas de $12,918 \mathrm{~nm}$ e diâmetro médio dos poros de $3,173 \mathrm{~nm}$, o que tornou plausível classificá-lo como um material predominantemente mesoporoso. $\mathrm{O}$ principal constituinte inorgânico determinado no carvão foi o fósforo (na forma de $\mathrm{P}_{2} \mathrm{O}_{5}$ ). $\mathrm{O}$ pH ponto de carga zero obtido para o carvão ativado foi igual a 2 , sendo neste mesmo $\mathrm{pH}$ obtida a maior remoção de fenol de soluções aquosas, cujo valor foi aproximadamente $81,6 \%$, indicando assim que este material possui um elevado potencial de remoção de fenol de soluções aquosas.

\section{REFERENCIAS}

ADINAVEEN, T.; KENNEDY, L. J.; VIJAYA, J. J.; SEKARAN, G. Studies on structural, morphological, electrical and electrochemical properties of activated carbon prepared from sugarcane bagasse. Journal of Industrial and Engineering Chemistry, v. 19, p. 14701476, 2013.

BEKER, U.; GANBOLD, B.; DERTLI, H.; GULBAYIR, D. D. Adsorption of phenol by active carbon: Influence of active methods and solution $\mathrm{pH}$. Energy Conversion and Management, v. 51, p. 235 -240, 2010.

DABROWSKI, A.; PODKOSCIENLNY, P.; HUBICKI, Z.; BARCZAK, M. Adsorption of phenolic compounds by activated carbon: a critical review. Chemosphere, v. 58, p. 10491070, 2005.

FERNANDEZ, M. E.; NUNELL, G. V.; BONELLI, P. R. Activated carbon developed from orange peels: Batch and dynamic competitive adsorption of basic dyes. Industrial Crops and Products, v. 62, p. 437-445, 2014.

GIRALDO, L.; MORENO-PIRAJÁN, J. C. Study of adsorption of phenol on activated carbons obtained from eggshells. Journal of Analytical and applied Pyrolysis, v. 106, p. 41-47, 2014.

GONDIM, J. A. M.; MOURA, M. F. V.; DANTAS, A. S.; MEDEIROS, R. L. S.; SANTOS, K. M. Composição centesimal e de minerais em cascas de frutas. Ciência e Tecnologia Alimentos, v. 25, p. 825-827, 2005.

GUIlARDUCI, V. V. S.; MESQUitA, J. P.; MARTElli, P. B.; GORGUlhO, H. F. Adsorção de fenol sobre carvão ativado em meio alcalino. Química Nova, v. 29(6), p. 1226-1232, 2006. 
INGLEZAKIS, V. J.; POULOPOULOS, S. G. Adsorption, ion Exchange and catalysis: Design of operations and environmental applications. Elsevier, $6^{\circ}$ edição, 2006.

JAGUARIBE, E. F.; MEDEIROS, L. L.; BARRETO, M. C. S.; ARAUJO, L. P. The performance of activated carbons from sugarcane bagasse, babassu, and coconut shells in removing residual chlorine. Brazilian Journal of Chemical Society, v. 22, p. 41-47, 2005.

KÖSEOGLU, E.; AKMIL-BASAR, C. Preparation, structural evaluation and adsorptive properties of activated carbon from agricultural waste biomass. Advanced powder Technology, v. 26, p. 811-818, 2015.

LORENC-GRABOWSKA, E.; GRYGLEWICZ, G.; DIEZ, M. A. Kinetics and equilibrium study of phenol adsorption on nitrogen-enriched active carbons. Fuel, v. 114, p. 235-243, 2013.

SCHNEIDER, E. L. Adsorção de compostos fenólicos sobre carvão ativado. Tese de Mestrado, UNIOESTE, Toledo-PR, 2008.

VIDIC, R. D.; SUIDAN, M. T.; BRENNER, R. C. Oxidative coupling of phenols on activated carbon: impact on adsorption equilibrium. Environmental Science Technology, v. 27, p. 2079-2085, 1993. 